\title{
A Case of Binder Syndrome: Rhinoplasty Surgeon's Perspective
}

\author{
Myeongsin Kang, Juyong Chung, Jin Yoon, and Jae Hoon Lee $\mathbb{E}$ \\ Department of Otolaryngology-Head and Neck Surgery, Institute of Wonkwang Medical Science, College of Medicine, \\ Wonkwang University, Iksan, Korea
}

\section{Binder 증후군 1예: 코 성형의사의 관점}

강명신 · 정주용 · 윤 진 · 이재훈

원광대학교 의과대학 이비인후과학교실, 의과학연구소

\author{
Received December 27, 2017 \\ Revised April 11, 2018 \\ Accepted April 23, 2018 \\ Address for correspondence \\ Jae Hoon Lee, MD, PhD \\ Department of Otolaryngology- \\ Head and Neck Surgery, \\ Institute of Wonkwang Medical \\ Science, College of Medicine, \\ Wonkwang University, \\ 895 Muwang-ro, Iksan 54538, Korea \\ Tel $+82-63-850-1441$ \\ Fax +82-63-841-6556 \\ E-mail leejaehoon64@gmail.com
}

Binder syndrome, also called the congenital flat nose syndrome, is a rare congenital malformation with a flat facial profile, intermaxillary hypoplasia and malocclusion. Rhinoplasty plays an important part in the multidisciplinary surgical protocol for this syndrome, for which weak nasal framework and soft tissue underdevelopment have been considered a great challenge. We present a case of Binder syndrome of a 27-year-old male. The nose was reconstructed with a caudal septum replacement graft and bilateral extended spreader grafts using costal cartilage.

Korean J Otorhinolaryngol-Head Neck Surg 2019;62(5):294-8

Key Words Binder syndrome $\cdot$ Congential $\cdot$ Flat nose.

\section{서 론}

Binder 증후군은 Zuckerkand1 ${ }^{1)}$ 에 의해 처음 기술이 되었으 며, 1962년 Binder ${ }^{2)}$ 가 처음으로 비상악골형성부전증(dysostosis maxillonasalis)이라 명명하였다. Binder 증후군은 비상 악골 형성 부전증(nasomaxillary hypoplasia)을 보이는 질환 으로 Crouzon 병이나 Apert 증후군과 같은 두개골 협착(craniostenosis)에서 와는 달리 비골과 이상구(piriform aperture) 주위에 있는 상악골에만 발육부전이 한정되어 있는 상태를 말한다. 이 증후군은 특징적으로 코가 낮아 선천성 접시 얼굴 (dish face) 또는 선천성 편평코 증후군(congenital flat nose syndrome)으로 불려 왔다. 이와 같이 코가 낮은 것 외에 이상 구 주위의 함몰, 비익저(alar base)와 외비공상(nostril sill)의

This is an Open Access article distributed under the terms of the Creative Commons Attribution Non-Commercial License (https://creativecommons.org/licenses/by-nc/4.0) which permits unrestricted non-commercial use, distribution, and reproduction in any medium, provided the original work is properly cited.
함몰, 짧은 비주(columella)와 예각의 비순각(nasolabial fold angle)이 특징이다. Binder 증후군에 대한 보고는 외국 문헌 에서는 종종 보고가 되어 왔으나, ${ }^{3-6)}$ 국내 이비인후과 관련 문헌에는 보고되지 않았다.

저자들은 Binder 증후군 환자에게 늑연골을 이용한 미측비 중격대체이식(caudal septum replacement graft)과 연장펼침 이식(extended spreader graft)을 사용하여 비교적 만족할만 한 결과를 얻었기에 문헌고찰과 함께 보고하는 바이다.

\section{증 례}

외국 국적의 27세 남자 환자로 어릴 때부터 인지한 낮은 코를 주소로 내원하였다. 과거력상 코를 다친 병력, 코 감염 혹은 외비성형술을 비롯한 코 수술의 기왕력은 없었으며 가 족력상의 특이소견도 없었다. 내원 당시 시행한 이학적 검사 상 심한 안장코(saddle nose)의 양상과 짧은 비주, 초승달 모 
양의 콧구멍, 그리고 안면 중부의 형성부전에 의한 하악의 상 대적인 돌출 소견을 나타냈다(Figs. $1 \mathrm{~A}$ and $\mathrm{B}, 2 \mathrm{~A}$ and $\mathrm{B}$ ). 비내시경 검사에서 우측으로의 경도 비중격 만곡증이 관찰 되었다. 이러한 임상소견들은 Binder 증후군에 적합하였다.
환자는 외비에 대한 수술적인 교정을 원하였다.

전신마취하에 우선 6 번째 늑연골을 얻은 후 수술에 사용 할 미측비중격대체이식과 연장펼침이식에 각각 필요한 크기 보다 충분히 크게 자르고 다듬은 후 늑연골이 휘어지는지를
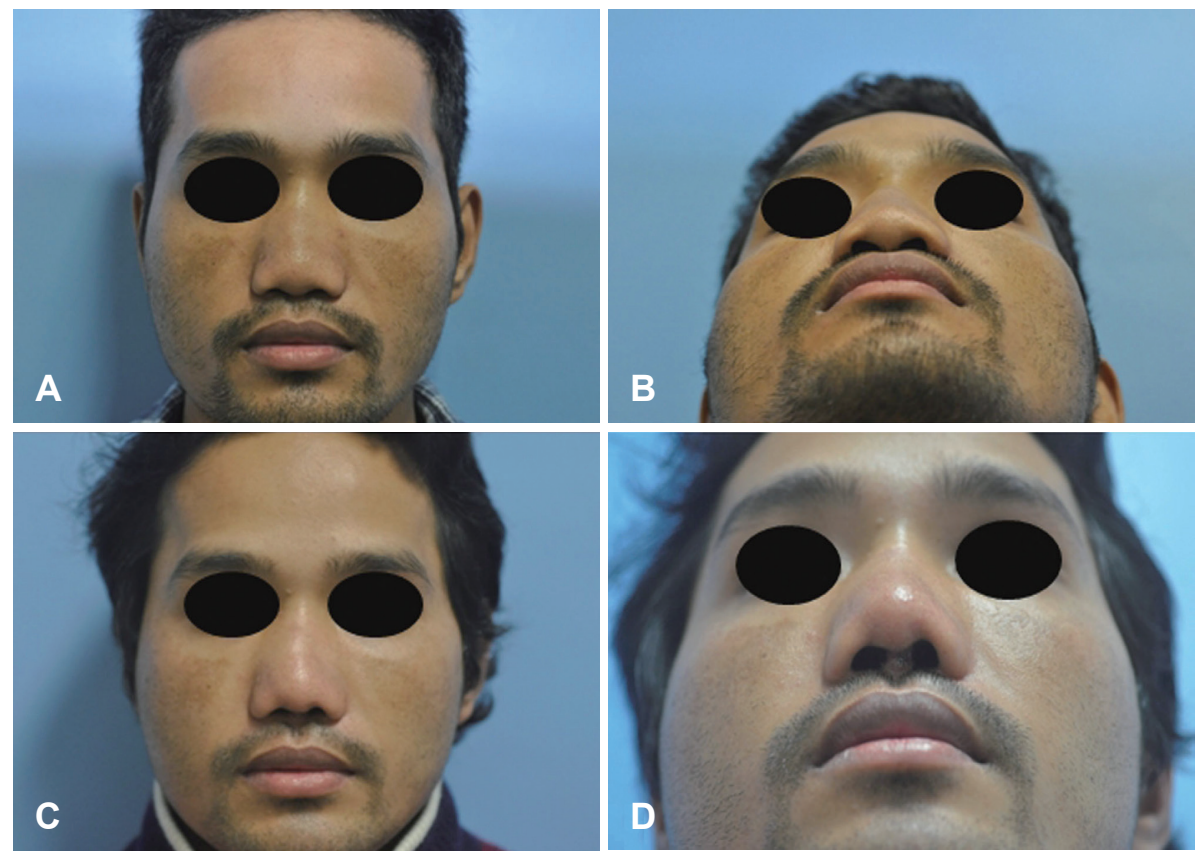

Fig. 1. Frontal (A) and basal (B) views of the nose shows flat nose and marked shortened columella. Three months after the rhinoplasty frontal (C) and basal (D) views of the nose show the aesthetic good results except columellar retraction.
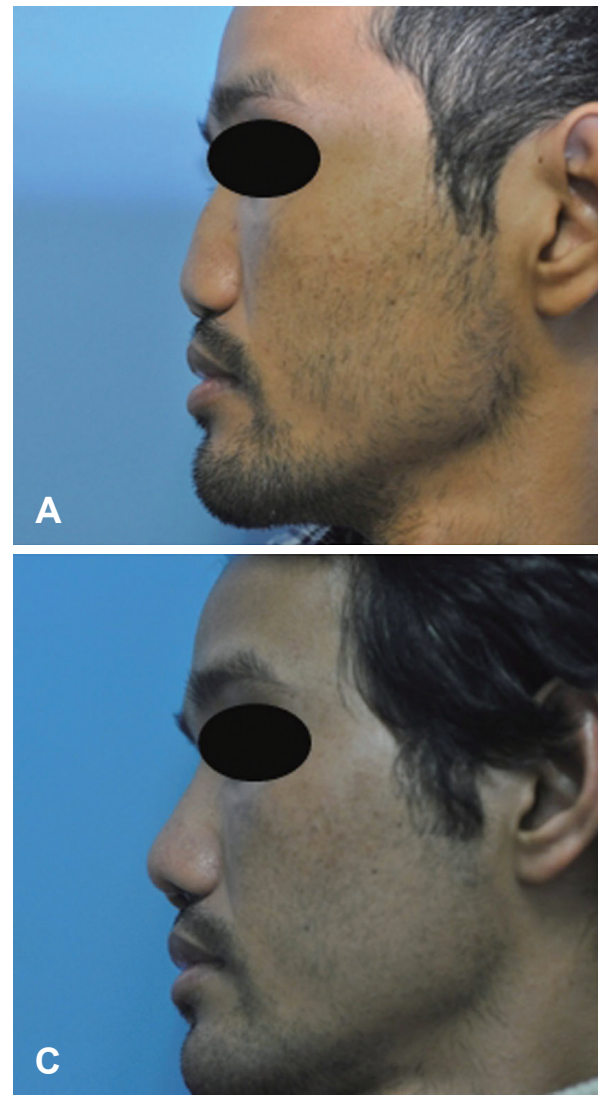
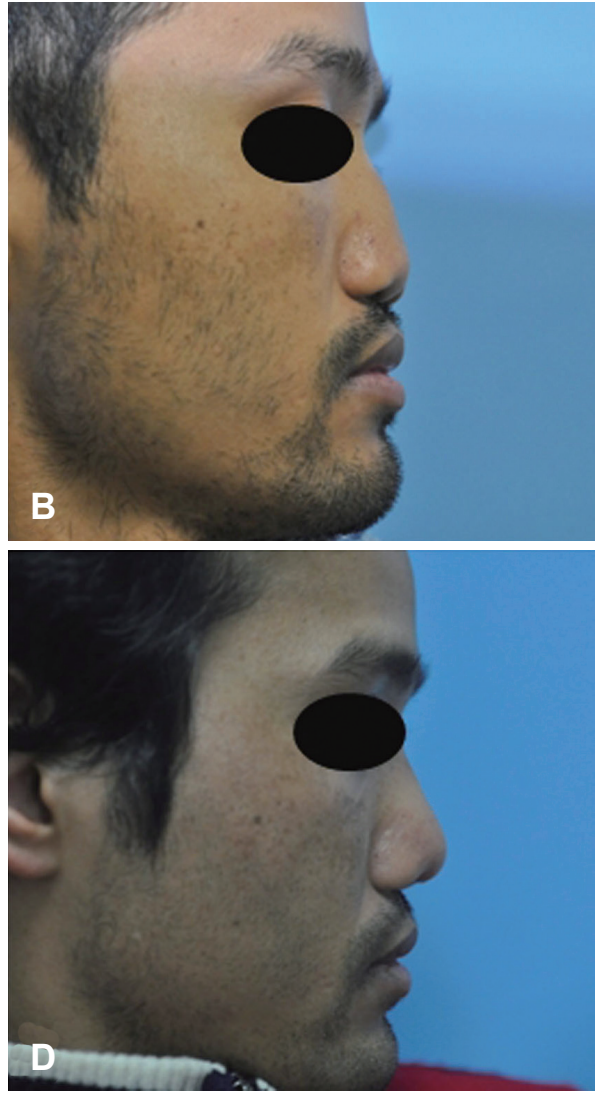

Fig. 2. Lateral (A and $B)$ views of the nose shows flat nose and marked shortened columella. Three months after the rhinoplasty lateral (C and D) views of the nose show the good profiles. 
확인하기 위해 생리 식염수에 담가두었다. 외비성형술은 매 우 짧은 비주의 길이 연장을 위해 역-V 모양의 경비주절개 대 신 $\mathrm{V}-\mathrm{Y}$ 피판을 위한 $\mathrm{V}$ 모양의 경비주절개와 변연절개를 가 하고 근건막층(musculoaponeurotic layer) 아래로 박리하여 하외측연골, 상외측연골과 비골을 순서대로 노출시켰다. 그 후 양측 하외측연골의 내측각 사이를 박리하여 미부 비중격 의 노출 없이 막성비중격(membranous septum)만을 박리하 여 충분히 공간을 노출시켰다. 그리고 양측의 비중격과 상외 측연골을 분리하여 연장펼침이식 부위의 공간을 확보하였다. 1 시간 정도 식염수에 담근 여러 조각들의 늑연골에서 휘어져 있는 부위를 제거하고 편평한 부위를 얻었다. 더마톰 블레이 드인 Zimmer ${ }^{\circledR}$ (Zimmer Surgical Inc., Dover, OH, USA)를 사용하여 미측비중격대체이식을 위해 $18 \times 11 \times 2 \mathrm{~mm}$ 크기로 한 개, 양측 연장펼침이식을 위해 $17 \times 4 \times 2 \mathrm{~mm}$ 크기로 두 개, 약간 우측으로의 휜 외비 변형 교정에 필요한 좌측 비배 측면중첨이식(lateral nasal wall graft)을 위해 $10 \times 8 \times 2 \mathrm{~mm}$ 크기로 한 개 준비하였다.

이식은 첫째, 막성비중격 부위에 미측비중격대체이식을 삽 입 후 tongue-in-groove 형태로 취하게 하고 하외측연골의 내 측각 발판(footplate)에서 주변 조직에 4-0 polydioxanon(PDS) 으로 잘 고정 봉합하였다(Fig. $3 \mathrm{~A})$. 둘째로 연장펼침이식은 비중격과 상외측연골의 사이의 양측에 삽입 후 4-0 polydioxanon(PDS)으로 비중격과 양측 상외측연골과 함께 잘 고정 한 후, 연장펼침이식의 말단부는 양측 하외측연골의 내측각 과 함께 미측비중격대체이식의 최상단으로부터 $5 \mathrm{~mm}$ 아래 에 고정하였다(Fig. $3 \mathrm{~B}$ ) . V-Y 피판을 위한 $\mathrm{V}$ 모양의 경비주절 개를 Y 모양으로의 봉합을 시도하였으나 발달이 거의 안 된 매우 짧은 비주로 인해 적절한 봉합이 잘 되지 않아 이차 치유 (secondary intention)를 기대하면서 수술을 마쳤다.

환자는 술 후 3 개월간 추적 관찰하였으며 늑연골이식에 따
른 감염, 휨과 같은 부작용은 발생되지 않았으나 비주 수축 은 관찰되었으며 비교적 결과에 만족하였다(Figs. $1 \mathrm{C}$ and D, $2 \mathrm{C}$ and $\mathrm{D}$ ). 환자는 비주 수축(columellar retraction)의 추가 적인 교정을 원하지는 않았으며 개인 사정상 고국으로 돌아 가서 더 이상 추적 관찰은 되지 않았다.

\section{고 찰}

Binder 증후군의 원인은 명확하지 않으나 임신 중 산모의 와파린 사용이나 페니토인 사용 등에 의한 비타민 $\mathrm{K}$ 결핍과 관련이 있을 것으로 추정되고 있다. ${ }^{7)}$

흰쥐에서 임신 초기에 와파린에 노출되면 비중격 연골의 길 이 성장의 장애가 발생하고 비정상적인 이상성 석회화가 발생 하는데, 이는 Binder 증후군의 임상 양상과 비슷하다. ${ }^{8)}$ 와파린 은 비타민 $\mathrm{K}$ 에폭사이드 환원효소(vitamin $\mathrm{K}$ epoxide reductase, $\mathrm{VKORC1)를} \mathrm{억제함으로써} \mathrm{비타민} \mathrm{K}$ 의 작용을 억제하 는 것으로 알려져 있다. 최근에 밝혀진 $\mathrm{VKORC1}$ 유전자의 돌연변이에서도 모든 비타민 $\mathrm{K}$ 의존성 단백의 기능장애가 증명되었다. ${ }^{9)}$ 한편, 임신 초기에 산모가 페니토인을 복용하는 경우에도 Binder 증후군이 보고되었는데 이는 페니토인이 비타민 $\mathrm{K}$ 의 산화적 분해를 야기하여 비타민 $\mathrm{K}$ 의 작용을 억 제하기 때문이다. ${ }^{10)}$ 결국, 임신 중 산모의 와파린 또는 페니토 인 등의 약물치료는 Binder 증후군의 위험인자이다. 비타민 $\mathrm{K}$ 의 흡수장애나 작용장애 또는 비타민 $\mathrm{K}$ 관련 유전자의 돌 연변이에 의해 주산기에 발달하는 연골이 손상을 받으면 연 골의 골 형성장애와 이상성 석회화 등의 이상을 보이게 되는 데 이러한 결과로 나타나는 임상 양상이 Binder 증후군일 것 으로 추정된다.

Binder 증후군의 징후들은 크게 3가지로 코의 형성부전, 이상구주위의 형성부전에 의한 편평한 코 주위, 부정교합이
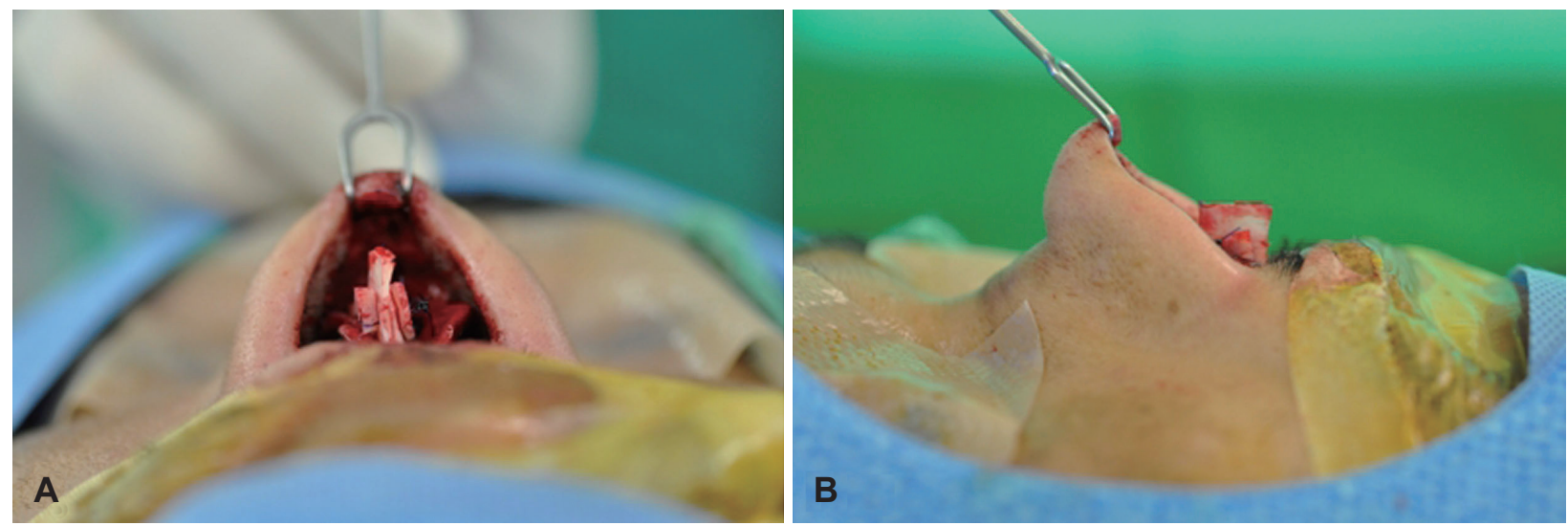

Fig. 3. Nasal dorsum and septum were reconstructed with caudal septum replacement graft and bilateral extended spreader grafts using costal cartilage ( $A$ and $B)$. 
동반된 함몰된 상악골로 구별되며, 이에 대한 교정이 필요하 다. 첫째, 짧고 편평한 비배부, 낮은 비첨 및 작은 비주와 같은 코의 형성부전은 자가골이나 자가연골을 이식하거나 무생물 재료(alloplastic material)를 삽입하여 교정하며, 둘째, 형성 부전이 있는 이상구 주위의 증대도 비성형술처럼 자가골이나 자가연골이식술 또는 무생물재료이식술을 이용할 수 있으며, 셋째, 부정교합이 동반된 심한 상악골의 형성부전은 상악절 골술로써 교정이 가능하다. 본 증례에서는 부정교합이 심하지 않았고 코의 형성부전만을 교정하고자 내원하였기 때문에 치과와의 협진 없이 코의 형성부전에 대한 수술만을 하였다.

Binder 증후군에서 코의 형성부전에 대한 재건술의 시기 는 조기 재건술과 지연 재건술로 구분할 수 있는데 성인이 될 때까지 기다리는 지연 재건술이 조기 재건술보다 더 우수하 다고 생각된다. ${ }^{11)}$ 그 이유로는 첫째, 조기 재건술을 시행한 두 개안면 증후군(craniofacial syndrome) 환자들에서 재수술 하는 경우가 많고, 둘째, 조기 재건술로 인한 코 내부의 반흔 조직으로 재수술이 어려울 수 있고, 셋째, 조기 재건술에 사 용한 이식물의 골절 혹은 이동의 염려로 소아 및 청소년기에 체육활동 등에 제한을 받을 수 있기 때문이다.

코의 형성부전에 대한 교정을 위해 Binder 증후군 환자는 2가지 측면에서 관심을 두어야 한다. 첫째, 비중격의 지지구 조와 비배부 구조의 복원이다. 둘째, 비주의 연부조직 부족 이다. 발달이 거의 되어 있지 않은 매우 짧은 비주로 인해 비 배부의 구조와 비중격 지지 복원에 필요한 연골 등의 이식 후 에 발생할 수 있는 비주의 절개 부위에 대한 봉합의 어려움과 비주 수축 문제이다.

Han 등 ${ }^{12)}$ 은 비배부 증대 및 연장을 위하여 실리콘고무(7 예), 두정골외판(5예), 늑골(1예)과 우형수산화인회석(bovine hydroxyapatite, Surgibone ${ }^{\circledR}$ (1예)을, 비주를 연장하기 위하여 고밀도다공성폴리에틸렌판(porous high density polyethylene sheet, Medpor $\left.{ }^{\circledR}\right)(3$ 예), 두정골외판(2예), 비중격연골(2예)과 늑연골(1예)을, 연조직피복을 위하여 전두피판술(1예)을, 그리 고 비첨돌출을 위하여 이개연골(3예), 늑연골(1예), 측두근막(1 예), 무세포동종진피(acellular allogenic dermis, Alloderm ${ }^{\circledR}$ ) (1예)와 전두피판술(1예)을 사용하였다. 1예에서 실리콘고무 가 노출되는 부작용이 발생되어 늑골과 늑연골로 대치하였 고, 2예에서 재수술을 하였는데, 좀 더 높은 코를 원하여 비 배부에 이식했던 두정골 외판에 실리콘고무를 추가적으로 삽입하였다. Kang 등흐는 코의 변형이 심하지 않은 Binder 증 후군 환자에서 실리콘 보형물 밑에 얇은 고밀도다공성에틸렌 판으로 강화하여 비중격 지지 복원 없이 비교적 간단한 비교 정술로 좋은 결과를 얻을 수 있었다고 보고하였다. Tian 등이 은 25예의 Binder 증후군 환자 중 9예에서 L자 모양의 실리
콘과 이개연골을 사용하였고, 16 예에서 늑연골을 사용하여 코 재건술을 하였는데 늑연골을 사용한 경우에서 보다 좋은 결과를 보였다고 보고하였다. Foda ${ }^{14)}$ 는 미부 비중격 지지가 소실된 93예에서 미측비중격대체이식을 시행하였는데 74예 (86\%)에서 코막힘 해결과 함께 미용적으로 만족스러운 결과 를 보고하였다. Binder 증후군에서와같이 강력한 비중격 지 지가 필요한 경우 비중격연골보다 늑연골사용이 보다 적합할 수 있다.

비주의 연부조직 부족에 대한 교정이 Binder 증후군 환자 에서 직면한 중요한 문제일 수 있다. Holmström ${ }^{15)}$ 은 Binder 증후군 환자에서 실제 비주의 연부조직이 부족하지 않으며 저형성된 비강저로 비주가 단순히 함몰되어 있다고 주장하 였으나, 비주의 연부조직의 실제 부족을 보고한 연구들이 있 다. ${ }^{5,6)}$ 비주의 길이 연장을 위한 술식으로 유리이개이식(free auricular graft), 윗입술로부터 작은 피판, $\mathrm{V}-\mathrm{Y}$ 피판, 비강저 로부터 작은 양측성 피판 및 전두피판(forehead flap)과 같 은 다양한 술식들이 시도되고 있으나 만족스러운 결과를 얻기 어려운 경우가 많다.5,6) 본 증례에서 비주 길이 연장을 위해 $\mathrm{V}-\mathrm{Y}$ 피판을 시도하였으나 만족스러운 결과를 얻지 못했다.

본 증례를 요약하면, 저자들은 Binder 증후군에서의 편평 한 코를 늑연골을 이용한 미측비중격대체이식과 연장펼침이 식 후 비교적 만족할만한 결과를 얻었다. Binder 증후군에서 비주의 연부조직 부족에 따른 비주 연장에 필요한 다양한 술식들을 수술 전에 충분히 숙지하고 수술에 적용해야 할 것 으로 생각된다.

\section{Acknowledgments}

This paper was supported by Wonkwang University in 2019.

\section{ORCID}

Jae Hoon Lee

https://orcid.org/0000-0002-0856-8173

\section{REFERENCES}

1) Zuckerkandl E. Fossae praenasales: normale und pathologische. Anat Nasenhohle 1882;1:48.

2) Binder KH. [Dysostosis masillo-nasalis, ein arhinencephaler Missbildungskomplex]. Deutsch Zahnaertzl Z 1962;17:438-44.

3) Holmström H, Gewalli F. Long-term behavior of three different grafts in nasomaxillary reconstruction of binder syndrome: an analysis by digitalized measurements. Plast Reconstr Surg 2008; 122(5):1524-34.

4) Gewalli F, Berlanga F, Monasterio FO, Holmström H. Nasomaxillary reconstruction in Binder syndrome: bone versus cartilage grafts. A longterm intercenter comparison between Sweden and Mexico. J Craniofac Surg 2008;19(5):1225-36.

5) Chummun S, McLean NR, Nugent M, Anderson PJ, David DJ. Binder syndrome. J Craniofac Surg 2012;23(4):986-90.

6) Tian L, You J, Wang H, Zhang B, Xu Y, Lu X, et al. Comparison of two different grafts in nasal framework reconstruction of Binder syndrome: cartilage and silicone. J Craniofac Surg 2017;28(6):1413-7. 
7) Khau Van Kien P, Nivelon-Chevallier A, Spagnolo G, Douvier S, Maingueneau C. Vitamin K deficiency embryopathy. Am J Med Genet 1998;79(1):66-8.

8) Howe AM, Webster WS. The warfarin embryopathy: a rat model showing maxillonasal hypoplasia and other skeletal disturbances. Teratology 1992;46(4):379-90.

9) Rost S, Fregin A, Ivaskevicius V, Conzelmann E, Hörtnagel K, Pelz $\mathrm{HJ}$, et al. Mutations in VKORCl cause warfarin resistance and multiple coagulation factor deficiency type 2. Nature 2004;427(6974):537-41.

10) Howe AM, Lipson AH, Sheffield LJ, Haan EA, Halliday JL, Jenson F, et al. Prenatal exposure to phenytoin, facial development, and a possible role for vitamin K. Am J Med Genet 1995;58(3):238-44.
11) Forrest CR, Hopper RA. Craniofacial syndromes and surgery. Plast Reconstr Surg 2013;131(1):86e-109e.

12) Han K, Cha M, Ham H. Reconstruction of Binder's syndrome with various surgical techniques: photogrammetric analysis of nasomaxillary bone. J Korean Soc Plast Reconstr Surg 2003;30;(4):384-92.

13) Kang SY, Lee W, Cho SH. Simple correction method of Binder's syndrome. Arch Craniofac Surg 2003;4;(2):121-5.

14) Foda HM. The caudal septum replacement graft. Arch Facial Plast Surg 2008;10(3):152-7.

15) Holmström H. Surgical correction of the nose and midface in maxillonasal dysplasia (Binder's syndrome). Plast Reconstr Surg 1986; 78(5):568-80. 